\title{
Metoclopramide-induced acute dystonic misinterpreted as conversion disorder and seizure
}

\author{
Betül Akbuğa Özel ${ }^{1}$, Gökhan Aksel ${ }^{2}$, Elif Kılıçlı ${ }^{1}$, Murat Muratoğlu ${ }^{1}$, Cemil Kavalcı ${ }^{1}$, Betül Gülalp ${ }^{1}$, Afșin Emre Kayipmaz ${ }^{1}$
}

\section{ABST RACT}

Metoclopramide, an antiemetic, is the most common cause of drug-induced dystonic reactions.

20-year-old female patient, complaining of involuntary bilateral upward medial deviation of the eyes, generalized muscle contractions and uncontrollable cry was brought into the emergency department(ED) by an ambulance. The diagnosis of the ambulance crew was conversion or seizure. The patient has all of dystonic reaction symptoms, including facial, neck, back, and extremity spasms, opisthotonus, oculogyric crisis, torticollis, trismus. The history revealed 40 mg of metoclopramide intake. Biperiden $(5 \mathrm{mg}$ ) was infused in $100 \mathrm{ml}$ saline. Symptoms were completely resolved. She was discharged from the ED.

Drug-induced dystonic reactions can be confused with conversion, seizures, encephalitis, tetanus and hypocalcemic tetany. It is important for emergency physicians to know the drugs that may have dystonic reaction as potential side effects, recognize the clinical presentation of drug-induced dystonic reactions, and properly manage them in the ED.

Keywords: dystonia, metoclopramide, misdiagnosis

\section{INTRODUCTION}

Metoclopramide is a dopamine- 2 antagonist and is commonly used for symptomatic treatment of gastrointestinal conditions. Its side effects include development of extrapyramidal contractions or increase in similar existing dysfunctions (1). Acute dystonic reactions (ADR) are the most common types of extra-pyramidal symptoms caused by metoclopramide.

We present a case in which a 20-year-old female patient who suffered metoclopramide induced ADR was brought into the emergency department with involuntary bilateral upward medial deviation of the eyes, generalized muscle contractions and uncontrollable cry was brought into the emergency department by an ambulance crew and was misdiagnosed as having conversion disorder and epileptic seizure. Written consent was obtained from our patient.

\section{CASE PRESENTATION}

Upon arrival, the vital signs of the patient were as follows: blood pressure $129 / 47 \mathrm{mmHg}$, pulse 81 beats per minute, respirations 20 breaths per minute, oxygen saturation $97 \%$ and temperature $36 \circ \mathrm{C}$. On physical exam, patient was found to be fully alert and cooperative with Glasgow Coma Scale of 15 . Her pupils were equal and reactive to light bilaterally. Both of her eyes deviated upward and medially (Figure 1), the neck was hyper-extended and deviated to the left. The patient was able to follow objects with her eyes upon command, but both eyes were deviating when they were not focused on any object. Same was true for her neck which was deviated to left without verbal orders to keep it inline (Figure 2). The patient's tongue was protruding periodically, she had spasms in her facial, neck, upper and lower back, extremities and experiencing opisthotonus, trismus and dysarthria. All four extremities of the patient were responding to verbal orders as much as her spasms allowed. Deep tendon reflexes were equal and normal in extremities. Sensory and cerebellar system examination was unremarkable, as with the rest of the physical exam. Laboratory exam results included complete blood count and biochemical parameters and they were all within normal limits.

The patient's history revealed that she had had diarrhea and vomiting for two days prior to ED presentation and she was taking $10 \mathrm{mg}$ metoclopramide, PO twice daily, prescribed by her family physician. Her present complaints started abruptly after taking the fourth metoclopramide tablet, 30 minutes prior to the ED arrival. The patient denied loss of consciousness and head injury. Her family history and history of medical conditions were negative. She was not on any medication besides metoclopramide at the time of ED visit.

The ED diagnosis for the patient was metoclopramide induced ADR. A total of $5 \mathrm{mg}$ biperiden was infused intravenously in $100 \mathrm{ml}$ normal saline over 20 minutes. Her symptoms were completely resolved following the infusion and she was discharged from the ED free of symptoms and complaints.

\section{DISCUSSION}

The incidence of metoclopramide induced ADR is around $0.2 \%$ and it is more frequently observed in women (2). The incidence of development of metoclopramide induced extrapyramidal reactions in very young and very old is $25 \%$ (3).

Acute dystonic reactions present with contractions in the face and neck, involuntary extremity movements, opisthotonus, torticollis, oculogyric crisis, bulbar type speech (mumbling, slurred, soft speaking with difficulty swallowing), trismus, protruding tongue and seldom stridor and dyspnea caused by laryngospasm $(4,5)$. Our patient exhibited all of the above symptoms, including facial, neck, back, and extremity spasms, oculogyric crisis, torticollis, trismus, protruding tongue and dysarthria, and it was considered a seldom occurrence.

Oculogyric crisis characterized by bilateral upward elevation of the eyes and hyperextension of the neck, can be

\footnotetext{
Baskent University, Medical Faculty, Department of Emergency Medicine, Ankara, Turkey

Ümraniye Training and Research Hospital, Emergency Medicine Clinic, Istanbul, Turkey 


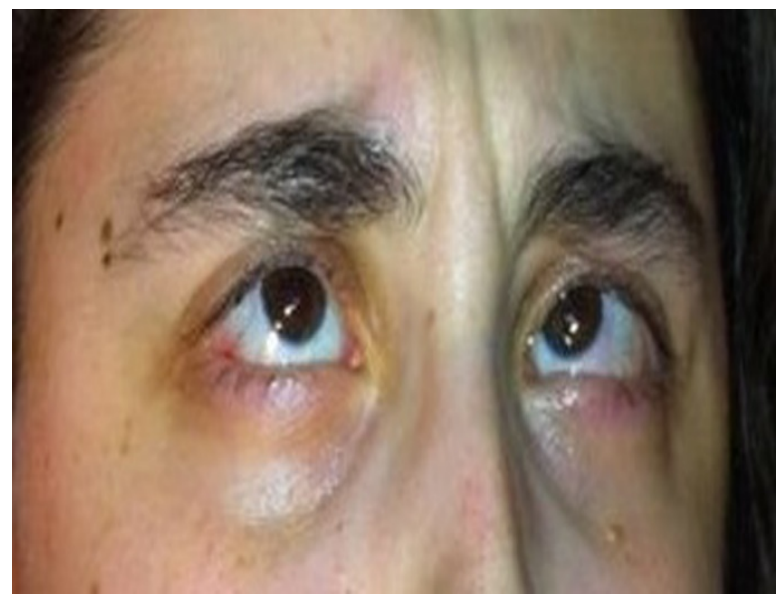

Figure 1: The view of oculogyric crisis

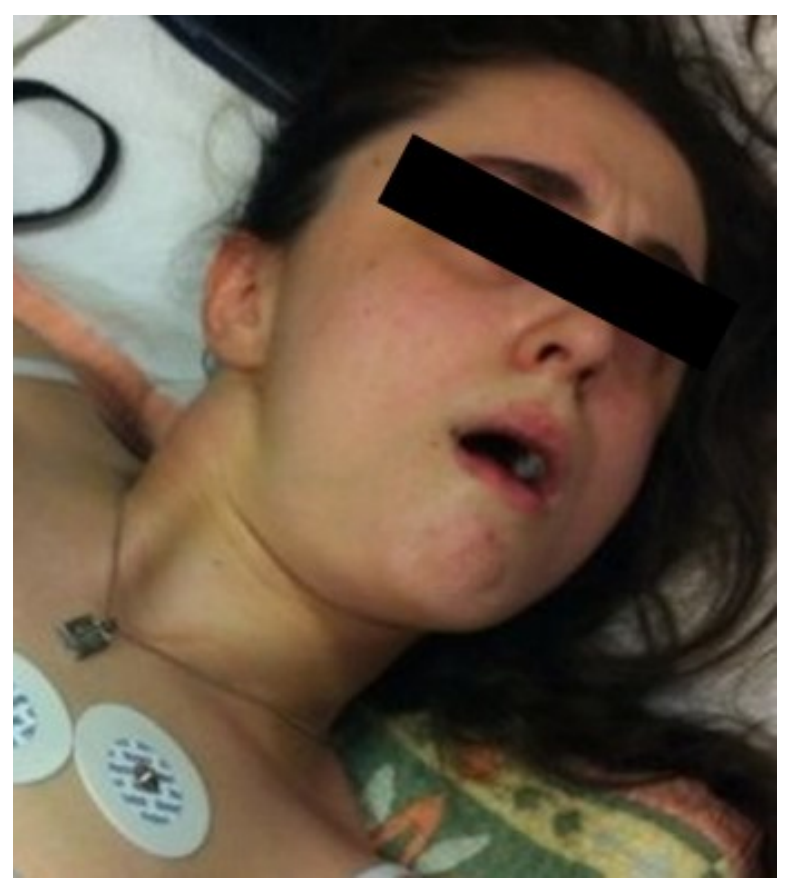

Figure 2: The view of torticollis and trismus

seen, just as any other extra-pyramidal side effects, after intake of single dose of metoclopramide $(6,7)$. A study

\section{REFERENCES}

1. Miller LG, Jankovic J. Metoclopramide-induced movement disor-ders. Clinical findings with a review of the literature. Arch Intern Med. 1989;149:2486-92.

2. Yis U, Ozdemir D, Duman M, Unal N. Metoclopramide induced dystonia in children: two case reports. Eur J Emerg Med. 2005; 12: 117-119

3. Hagen EM, Farbu E, Bindoff L. Acute dystonia caused by metoclopramide therapy. Tidsskr Nor Laegeforen. 2001; 121:2162-3.

4. Bateman DN, Rawlins MD, Simpson J M. Extrapyramidal reactions with metoclopramide. BMJ . 1985;291:930-2

5. Karagoz G, Kadanali A, Dede B, et al. MetoclopramideInduced Acute Dystonic Reaction: A Case Report. EAJ M. 2013; 45:58-9. conducted by Guala (8) reports that when metoclopramide intake exceeds the recommended doses, the side effects are seen more commonly in females between 12 and 19 years old and those with family history of neurological disorders. The drug is also reported to have accumulative effects in repeating doses. Van Der Padt et al. (9) reported that metoclopramide induced ADR can be seen in patients with genetic polymorphism in CYP2D6 gene. Both of these studies suggest stopping or careful use of metoclopramide in family members in which ADR is developed in a family member $(8,9)$.

Acute dystonic reactions secondary to metoclopramide use develops during the first 24 hours following intake in $63 \%$ of the cases and during the first 72 hours in $94 \%$ of the cases (4). Our patient developed ADR in 48 hours following the use of the first dose.

The general management of metoclopramide induced ADRs include administration of diphenhydramine, biperiden, benztropine, and finally diazepam in rare refractory cases. Our patient was treated successfully with biperiden.

Acute dystonic reactions can be confused with conversion disorders, seizures, encephalitis, tetanus and hypocalcemic tetany $(1,7,10)$. Our patient was brought into the emergency department by an emergency ambulance crew, with the initial diagnoses of conversion and epileptic seizure. The patient handovers with misdiagnoses can cause misconditioning, difficulty in accurate diagnosis, unnecessary use of resources, and extension of ED stay for patients. For these reasons, emergency clinicians master the differences in clinical presentations of acute dystonic reactions and other conditions considered in differential diagnosis by completing thorough physical assessment and obtaining complete history.

\section{CONCLUSION}

Emergency clinicians should be proficient in clinical presentations of drug induced ADR, drugs that can potentially cause ADR, differential diagnoses of ADR and emergency management of these reactions. Considering metoclopramide, a commonly prescribed medication, as the most common cause of ADR is important for the ED staff, as it has high risk for misdiagnosis.

\section{CONFLICT OF INTEREST}

The authors declare that there is no conflict of interest regarding the publication of this manuscript.

6. Edwards M, Koo MW, Tse RK. Oculogyric crisis after metoclpramide therapy. Optometry and Vision Science. 1989;66(3):179-80.

7. Walker M, Samii A. Chronic severe dystonia after single exposure to antiemetics. Am J Emerg Med. 2006;24:1257.

8. Guala A, Mittino D, Ghini T, Quazza G. Are metoclopramide dystonias familial? Pediatr Med Chir. 1992; 14:617-618.

9. Van Der Padt A, Van Schaik RH, Sonneveld P. Acute dystonic reaction to metoclopramide in patients carrying homozygous cytocrome P450 2D6 genetic polymorphisms. J Medicine. 2006;64:160-2.

10. Arumugam J, Vijayalakshmi AM. Metoclopramideinduced oculogyric crisis presenting as encephalitis in a young girl. Indian J Pharmacol. 2012;44(2):266-7. 